\title{
A proposal for the withdrawal of inhaled corticosteroids in the clinical practice of chronic obstructive pulmonary disease
}

\author{
Marc Miravitlles ${ }^{1 *}$ D, Borja G. Cosío ${ }^{2,3}$, Aurelio Arnedillo ${ }^{4,5}$, Myriam Calle ${ }^{6,7}$, Bernardino Alcázar-Navarrete ${ }^{8}$, \\ Cruz González ${ }^{9}$, Cristóbal Esteban 10,11, Juan Antonio Trigueros², José Miguel Rodríguez González-Moro ${ }^{13}$, \\ José Antonio Quintano Jiménez ${ }^{14}$ and Adolfo Baloira ${ }^{15}$
}

\begin{abstract}
According to the current clinical practice guidelines for chronic obstructive pulmonary disease (COPD), the addition of inhaled corticosteroids (ICS) to long-acting $\beta_{2}$ agonist therapy is recommended in patients with moderate-tosevere disease and an increased risk of exacerbations. However, ICS are largely overprescribed in clinical practice, and most patients are unlikely to benefit from long-term ICS therapy.

Evidence from recent randomized-controlled trials supports the hypothesis that ICS can be safely and effectively discontinued in patients with stable COPD and in whom ICS therapy may not be indicated, without detrimental effects on lung function, health status, or risk of exacerbations. This article summarizes the evidence supporting the discontinuation of ICS therapy, and proposes an algorithm for the implementation of ICS withdrawal in patients with COPD in clinical practice.

Given the increased risk of potentially serious adverse effects and complications with ICS therapy (including pneumonia), the use of ICS should be limited to the minority of patients in whom the treatment effects outweigh the risks.
\end{abstract}

Keywords: Algorithm, Chronic obstructive pulmonary disease, Exacerbations, Inhaled corticosteroids, Lung function

\section{Background}

Chronic obstructive pulmonary disease (COPD) is associated with high morbidity and mortality worldwide, [1] and continues to represent a significant public health challenge. According to the Global Initiative for Chronic Obstructive Lung Disease (GOLD) recommendations, long-acting bronchodilators are the mainstay of treatment in patients with COPD [2]. Similarly, all national guidelines for the management of COPD in Europe recommend bronchodilators as first-line therapy, regardless of clinical presentation or phenotype [3].

Anti-inflammatory therapy with inhaled corticosteroids (ICS) may be added to long-acting $\beta_{2}$-agonists (LABAs) in

\footnotetext{
* Correspondence: mmiravitlles@vhebron.net

'Pneumology Department, Hospital Universitari Vall d'Hebron, P. Vall d'Hebron 119-129, 08035 Barcelona, Spain

Full list of author information is available at the end of the article
}

patients with moderate-to-very severe COPD and exacerbations [2]. The ICS/LABA combination is more effective than either of the individual drugs alone for improving health status and lung function and reducing exacerbations in these patients, [4-6] and may also be used in the management of patients with asthma-COPD overlap (ACO) $[2,7,8]$. However, regular ICS therapy is associated with an increased risk of pneumonia, particularly in older patients (aged $\geq 55$ years) and those with severe disease, as well an increased prevalence of oral candidiasis, skin bruising and hoarse voice $[2,9,10]$.

According to the GOLD strategy, patients with COPD in group D (with a history of frequent exacerbations $[\geq 2$ in the past year], and a COPD Assessment Test [CAT] score $\geq 10$ or modified Medical Research Council score $\geq$ 2) should receive first-line treatment with a LABA/longacting muscarinic antagonist (LAMA) combination [2]. ICS/LABA combination therapy may be considered as first-line therapy in patients with suspected ACO or high 
blood eosinophil counts $[2,8]$. Based on these combined risk criteria, real-life data indicate that only a minority of patients with COPD would be potential candidates for ICS therapy $[11,12]$. However, ICS prescribing rates (either alone or as combination therapy) reportedly range from $42 \%$ to $86 \%$, regardless of COPD severity and exacerbation risk $[7,13-18]$. This high ICS usage significantly increases the risk of serious pneumonia and other respiratory infections $[6,19,20]$.

In a 2015 Spanish consensus report, it was agreed that ICS therapy should be added to long-acting bronchodilators in patients with frequent exacerbations and in those with ACO phenotype, but should not be added to LABA therapy to improve lung function [21]. The expert panel also agreed that ICS withdrawal in patients with stable COPD was possible, although no consensus was reached on how, when and in whom to discontinue ICS [21]. Algorithms for the withdrawal of ICS in patients switched from GOLD D to C following the new GOLD classification [22] and for the stepwise ICS withdrawal in patients with COPD $[23,24]$ have previously been proposed; however, complex treatment algorithms are often difficult to adopt into clinical practice. To this end, simplified treatment algorithms for COPD management have been developed $[25,26]$.

As a follow-up to the previous Spanish consensus report on ICS use in COPD, experts in COPD management met with the aim of developing a simplified strategy for ICS withdrawal in patients with COPD. This article summarizes the evidence for the discontinuation of ICS therapy and presents a potential algorithm for the implementation of ICS withdrawal in clinical practice.

\section{Effects of ICS therapy in patients with COPD Anti-inflammatory effects}

ICSs are very effective as anti-inflammatory therapy in patients with asthma. ICS therapy works by recruiting histone deacetylase (HDAC) enzymes to inflammatory genes that are being actively transcribed; this suppresses the expression of inflammatory proteins and results in decreased airway inflammation [27]. Compared with asthma, ICS therapy is less effective when used in the management of COPD. The diminished anti-inflammatory effects of ICSs in COPD may be caused by decreased HDAC expression and enzyme activity, which has been observed in the alveolar macrophages of patients with COPD and is thought to be mediated by oxidative stress $[28,29]$.

Although the anti-inflammatory effects of ICS therapy are decreased in COPD compared with asthma, decreases in airway inflammation with ICS have been reported in patients with COPD. In a study of patients with moderateto-severe COPD, inhaled fluticasone/salmeterol for 13 weeks led to significant reductions in absolute biopsy $\mathrm{CD}^{+}, \mathrm{CD}^{+}$, and $\mathrm{CD} 45^{+}$cell counts versus placebo, as well as sputum differential neutrophil counts and sputum eosinophils [30]. The Groningen Leiden Universities Corticosteroids in Obstructive Lung Disease (GLUCOLD)-1 study has also shown significant reductions in sputum neutrophils, macrophages, and lymphocyte counts with fluticasone therapy over 30 months in patients with moderate-to-severe COPD, while withdrawal of fluticasone after 6 months led to increased bronchial $\mathrm{CD}^{+}$, mast, and plasma cell counts [31]. In a long-term observational follow-up study (GLUCOLD-2), patients who discontinued fluticasone after 30 months of treatment experienced an increase in sputum inflammatory cells, as well as bronchial T-lymphocytes and mast cells [32]. The GLUCOLD-2 study also demonstrated a significant correlation between increased sputum macrophage counts and an accelerated rate of decline in lung function [32]. These studies suggest that at least some patients with COPD, and in particular those with significant airway inflammation, may benefit from ICS therapy. However, there is also evidence that fluticasone may not affect airway inflammation. For example, a study of Japanese patients with COPD showed no significant changes from baseline in sputum neutrophils or other inflammatory markers with salmeterol/fluticasone for 12 weeks when compared with placebo [33].

Eosinophilic airway inflammation, which is commonly found in patients with asthma, also occurs in some patients with COPD [34]. High blood and/or sputum eosinophil counts are often associated with an increased risk of COPD exacerbations, $[35,36]$ and may be a marker of response to ICS therapy [37-39].

\section{Clinical effects}

Early randomized-controlled trials (RCTs) have demonstrated the clinical benefits of inhaled fluticasone propionate in patients with moderate-to-severe COPD [40, 41]. In these trials, fluticasone was associated with significantly lower rates of moderate or severe exacerbations compared with placebo over 6 months, [41] or 3 years [40].

Subsequent studies have shown that ICS/LABA combination therapy is more effective than ICS alone, particularly with regard to reducing exacerbations, [5] but has no effect on long-term survival. In the Towards a Revolution in COPD Health (TORCH) trial, fluticasone propionate/salmeterol was associated with a slight reduction in mortality risk compared with placebo, but this reduction was not statistically significant [42]. The mortality risk also did not significantly differ between fluticasone/salmeterol and salmeterol alone, but was significantly lower with the combination therapy than fluticasone alone ( $p=0.007)$ [42]. A subsequent analysis of data from the TORCH study suggested that any mortality 
benefit from fluticasone/salmeterol versus placebo was more likely attributable to the salmeterol component [43]. In the Study to Understand Mortality and Morbidity (SUMMIT) in patients with moderate COPD and increased cardiovascular risk, fluticasone furoate/vilanterol had no significant effect on allcause mortality or cardiovascular outcomes compared with placebo [44].

The beneficial effects of ICS therapy in preventing or reducing exacerbations appear to be limited to patients with eosinophilic inflammation. In a randomized study of patients with COPD, a $62 \%$ mean reduction in the frequency of severe exacerbations was observed when COPD management was aimed at minimizing sputum eosinophil levels compared with conventional guidelinebased management [45]. In a post hoc analysis of two randomized, double blind trials, the combination of vilanterol/fluticasone furoate was shown to reduce COPD exacerbations by $29 \%$ in patients with eosinophil counts of $\geq 2 \%$ and by $10 \%$ in patients with eosinophil counts of $<2 \%$ compared with vilanterol alone [46]. In a post hoc analysis of the Foster 48-Week Trial to Reduce Exacerbations in COPD (FORWARD), the beneficial effects of beclomethasone dipropionate/formoterol fumarate (ICS/LABA) versus formoterol fumarate alone with regard to reductions in exacerbations were most evident in patients with peripheral blood eosinophilia $(\geq 279.8$ cells $/ \mu \mathrm{L}$ ) [39]. Similarly, a pooled analysis of two 12month RCTs showed that patients with $>2.4 \%$ blood eosinophils potentially achieve the greatest reductions in exacerbations with ICS/LABA therapy versus LABA alone [38]. An analysis of the Inhaled Steroids in Obstructive Lung Disease in Europe (ISOLDE) trial indicated that a baseline blood eosinophil count $\geq 2 \%$ was associated with a significantly reduced rate of $\mathrm{FEV}_{1}$ decline with fluticasone propionate versus placebo $(p=$ 0.003), while there was no difference in $\mathrm{FEV}_{1}$ decline among those with $<2 \%$ eosinophils [37].

However, when comparing the efficacy of ICS with that of long-acting bronchodilators the results are usually favorable to the latter. LAMA alone has been shown to be as effective as ICS/LABA therapy with regard to improvements in lung function and preventing exacerbations in patients with COPD. In the Investigating New Standards for Prophylaxis In Reducing Exacerbations (INSPIRE) study of patients with severe or very severe COPD and a history of exacerbations, the annual rate of exacerbations showed no difference between fluticasone propionate/salmeterol and tiotropium bromide alone, although the incidence of pneumonia was significantly higher with fluticasone propionate/salmeterol $(p=0.008)$ [47].

The LABA/LAMA combination indacaterol/glycopyrronium was associated with significantly greater improvements in lung function over 26 weeks compared with fluticasone/salmeterol $(p<0.001)$ in the Efficacy and safety of once-daily indacaterol/glycopyrronium compared with twice-daily salmeterol-fluticasone in patients with chronic obstructive pulmonary disease (ILLUMINATE) trial, [48] and significantly reduced the rate of moderate or severe exacerbations with a lower rate of pneumonia in A 26-week treatment randomized, double-blind, double dummy, parallel-group study to assess the efficacy and safety of indacaterol/glycopyrronium (LANTERN) trial [49]. In the Effect of indacaterol/glycopyronium vs fluticasone/salmeterol on COPD exacerbations (FLAME) trial, the annual rate of COPD exacerbations was also found to be significantly $(11 \%)$ lower with indacaterol/glycopyrronium than fluticasone/salmeterol over 12 months $(p=0.003)$ in patients with a previous history of at least one exacerbation. It is important to indicate that patients with a history of asthma and/or blood eosinophil counts $>600$ cells/ $\mu \mathrm{L}$ were excluded form FLAME [50].

\section{Adverse effects of inhaled corticosteroids}

Accumulated evidence from clinical trials indicates that ICS therapy is associated with a high risk of pneumonia, oral candidiasis, hoarse voice, and skin bruising $[2,4,5,9$, 10]. The risk of pneumonia is increased in older patients (aged $\geq 55$ years), current smokers, and patients with a history of exacerbations or pneumonia, a body mass index $<25 \mathrm{~kg} / \mathrm{m}^{2}$, dyspnea, and/or severe airflow limitation [2, 9]. In a meta-analysis of RCTs in patients with COPD, inhaled fluticasone or budesonide was associated with a significant (57\%) increase in the risk of pneumonia $(p<0.0001)$ [51]. However, an observational cohort study of patients with COPD found that the rates of pneumonia and hospitalization were significantly higher with fluticasone/salmeterol than budesonide/ formoterol $(p<0.001)$, which suggests there are intradrug class differences in the risks of pneumonia with ICS/LABA combination therapies [52].

Long-term ICS exposure may also be associated with an increased risk of bone fractures in patients with COPD [53]. A meta-analysis of RCTs and observational studies indicated a significant $(27 \%)$ increase in the risk of fractures with fluticasone or budesonide therapy $(p=0.04)$ [53]. Osteoporosis and COPD are also strongly correlated due to common lifestyle risk factors (eg physical inactivity, poor diet, and smoking), COPD-associated inflammation, and vitamin D deficiency [54].

Other adverse effects associated with the use of ICS include an increased risk of new-onset diabetes or diabetes progression, [55] cataracts, [56] and tuberculosis [57]. In a database cohort study of patients with respiratory disease, ICS therapy was associated with a $34 \%$ increase both in the risk of new-onset diabetes and in the risk of diabetes progression [55]. 


\section{Evidence supporting ICS withdrawal in patients with COPD}

The excessive and inappropriate use of ICS in COPD together with the increased risk of adverse effects associated with its use makes it necessary to discontinue this treatment in patients in which the risks overweight the possible benefits. Withdrawal of ICS has been analyzed in several studies.

In patients with COPD, ICS withdrawal was associated with several clinical disadvantages in early studies (Table 1). As part of the ISOLDE trial, [40] an observational study compared patients who were receiving ICS at study entry with those who were not on ICS [58]. In this 8-week study, ICS withdrawal was associated with more exacerbations, indicating that patients should be monitored carefully following abrupt ICS discontinuation [58]. In the Effect of discontinuation of inhaled corticosteroids in patients with chronic obstructive pulmonary disease (COPE) study, withdrawal of inhaled fluticasone led to a higher risk of exacerbation and a significant decline in quality of life [59]. Likewise, discontinuation of fluticasone was associated with a decline in lung function and an increase in dyspnea and mild exacerbations in the COPD and Seretide: a Multicenter Intervention and Characterization (COSMIC) trial, [60] and a worsening of symptoms and increased risk of exacerbations in the Withdrawal of inhaled corticosteroids in people with COPD in primary care (WISP) trial [61].

However, a meta-analysis of the WISP, COPE, and COSMIC trials indicated that ICS withdrawal was not associated with a significant increase in the risk of exacerbations [62]. The definition of exacerbation differed between these early studies and the use of other medication was not reported [62]. A more recent and robust meta-analysis concluded that ICS discontinuation did not significantly increased the overall rate of COPD exacerbations, although an increased risk of severe exacerbations was detected [63]. The increased risk of all types of exacerbations following ICS withdrawal observed in early studies was most likely due to a lack of alternative COPD medications.

Evidence from more recent RCTs and real-life studies supports the hypothesis that the ICS therapy can be safely withdrawn in patients with stable COPD (Table 1). In the Withdrawal of Inhaled Steroids During Optimized Bronchodilator Management (WISDOM) trial, in which the safety of gradual ICS withdrawal in patients previously on ICS/LABA/LAMA triple therapy was evaluated, there was no significant difference in the risk of moderate or severe COPD exacerbation over 12 months after ICS withdrawal compared with ongoing triple therapy [64]. Although a significantly greater decrease in $\mathrm{FEV}_{1}$ was observed at 18 weeks after ICS withdrawal (mean difference $38 \mathrm{~mL}$ vs continued ICS; $p<0.001$ ), [63] this was less than half of what is considered as the minimum clinically important difference. A post hoc analysis of WISDOM showed that patients who stopped ICS experienced a similar disease course with regard to lung function to those who continued ICS therapy [64]. Although deterioration of lung function was observed after ICS withdrawal, these changes were small, not progressive and not predictive of clinically important changes over the duration of study follow-up [65].

By contrast, in the Indacaterol: Switching Non-exacerbating Patients with Moderate COPD from Salmeterol/Fluticasone to Indacaterol (INSTEAD) trial, there were no clinically relevant reductions in lung function or differences in dyspnea or health status over 26 weeks among patients who switched to indacaterol compared with those who continued fluticasone/salmeterol therapy [66]. The annual rate of mild, moderate, or severe COPD exacerbations also showed no significant difference between the groups. The INSTEAD trial concluded that patients with moderate airflow limitation and no history of exacerbations can be switched from fluticasone/salmeterol to indacaterol monotherapy without loss in treatment efficacy [66].

In the Real-life study on the appropriateness of treatment in moderate COPD patients (OPTIMO), the risk of exacerbations did not significantly increase over 6 months after ICS withdrawal compared with continued ICS/bronchodilator therapy [67]. There was also no evidence of deterioration in COPD symptoms or lung function over 6 months following ICS withdrawal [67]. Consistent with these findings, a subgroup analysis of patients on ICS prior to study entry in the Outpatient care with long-acting bronchodilators: COPD registry in Germany (DACCORD) showed that ICS withdrawal was not associated with an increase in the risk of exacerbations or an increased risk of health status deterioration compared with continued ICS therapy [68]. Indeed, in the second year of follow-up in DACCORD, the annual rate of exacerbations was lower among patients who underwent ICS withdrawal than in those who continued ICS therapy [68].

ICS withdrawal may also provide clinical benefits in patients by reducing the risk of adverse effects, particularly pneumonia. In a population-based cohort study, ICS withdrawal in patients with COPD was associated with a $37 \%$ decrease in the rate of serious pneumonia over 3 years, with a $20 \%$ risk reduction over the first month [69]. Of note, patients who discontinued fluticasone showed greater reductions in severe pneumonia risk than those who discontinued budesonide [69]. These findings indicate that the beneficial effects of ICS withdrawal may occur soon after treatment discontinuation.

In a subanalysis of exacerbation rates by previous therapy in the FLAME trial, among patients who had previously 


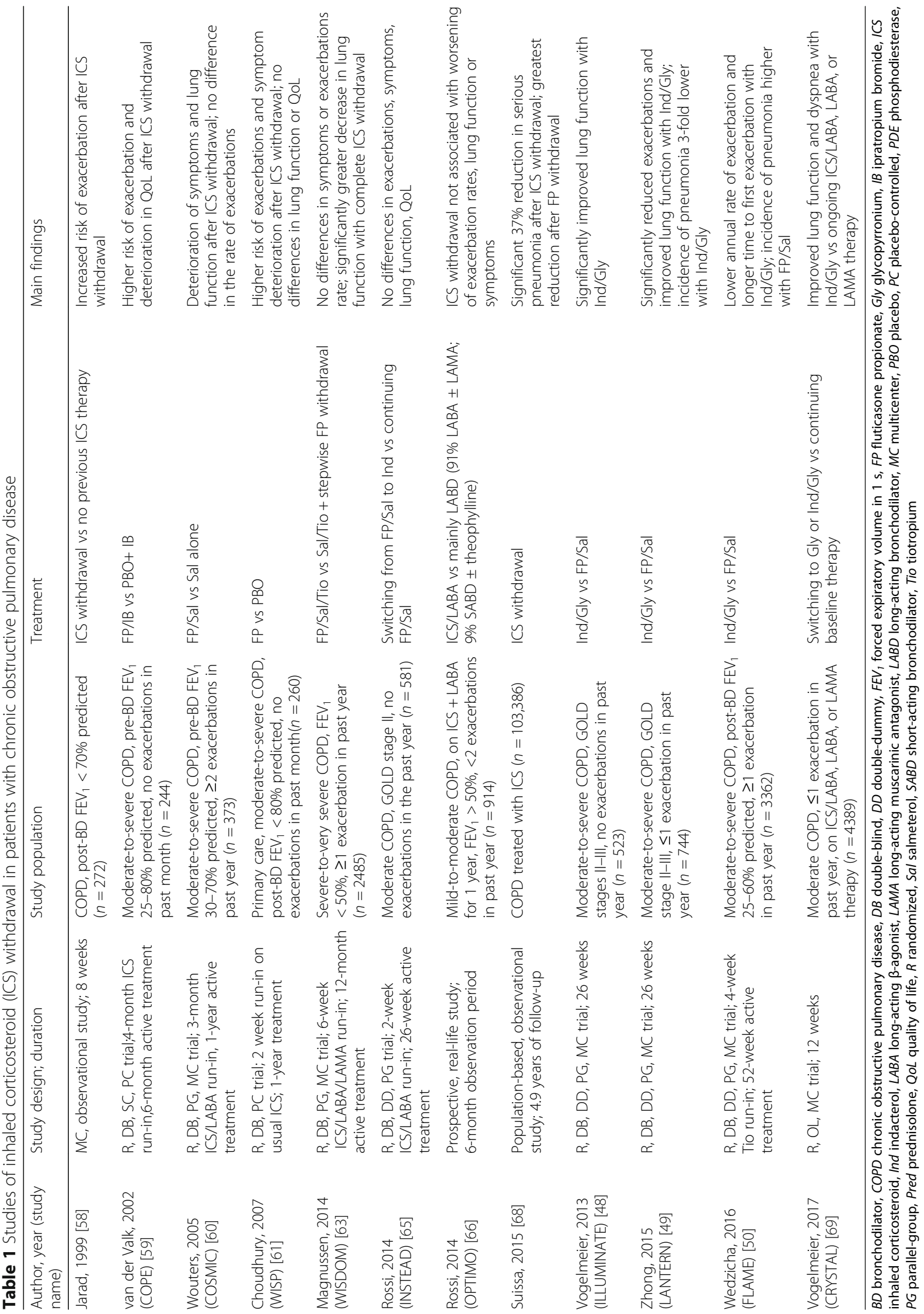


received ICS therapy (56\% of patients), those who were randomized to LABA/LAMA had a significantly lower risk of exacerbations than those who continued ICS/LABA therapy (risk ratio 0.88; 95\% confidence interval 0.80-0.97) [50]. Additionally, the effect of glyCopyrronium or indacateRol maleate and glYcopyrronium bromide fixed-dose combination on SympToms and heALth status in patients with moderate COPD (CRYSTAL) study of symptomatic patients with moderate COPD previously on ICS/LABA, LABA or LAMA therapy showed that switching to indacaterol/glycopyrronium was associated with significant improvements in trough $\mathrm{FEV}_{1}$ over 12 weeks [70].

In a subanalysis of the WISDOM study, patients with severe or very severe COPD and a history of exacerbations who had blood eosinophil counts of $\geq 4 \% \quad(\geq 300$ cells $/ \mu \mathrm{L}$ ) were at an increased risk of exacerbations following ICS withdrawal compared with those with lower eosinophil counts [71]. In fact, the risk of exacerbation after withdrawal was significantly increased in patients who suffered 2 or more exacerbations the previous year and had blood eosinophil counts $>300$ cells $/ \mu \mathrm{L}$. In addition, these patients experienced a mean decrease of $109 \mathrm{~mL}$ in FEV1 compared with the mean decrease of $43 \mathrm{~mL}$ for the whole population [72]. This suggests that ICS withdrawal may have deleterious effects in a subpopulation of patients with higher blood eosinophil counts and frequent exacerbations.

\section{Proposed algorithm for ICS withdrawal in patients with COPD}

The proposal for managing ICS withdrawal in patients with COPD takes three clinical parameters into account: a) whether or not there is a history of previous exacerbations; b) whether $\mathrm{FEV}_{1}$ is more or less than $50 \%$; and c) whether the patient has criteria for ACO (which in the Spanish guidelines includes patients with COPD and blood eosinophil counts $>300$ cells $/ \mu \mathrm{L}$ and/or a postbronchodilator response of $>400 \mathrm{~mL}$ and $15 \%$ in $\mathrm{FEV}_{1}$ ) [73]. Based on these clinical parameters, patients with COPD may be classified into three categories: (i) patients in whom the risks associated with ICS withdrawal exceed the benefits; (ii) those in whom the benefits of ICS withdrawal are greater than the risks; and (iii) those in whom the risks and benefits of ICS are balanced. A summary of this patient classification and how lung function and exacerbation history affect the benefits and risks of ICS withdrawal is shown in Fig. 1. Taking these categories into consideration, the decision to withdraw or continue ICS is based on the following:

1. In patients with COPD, $\mathrm{FEV}_{1}>50 \%$ and no previous exacerbations, the benefits of ICS withdrawal exceed risks and ICS must be withdrawn.
2. In patients with $\mathrm{ACO}$ and exacerbations in the previous year, the risks associated with ICS withdrawal exceed the benefits and ICS should not be withdrawn.

3. Patients with $\mathrm{FEV}_{1}>50 \%$ and exacerbations in the previous year and patients with $\mathrm{FEV}_{1}<50 \%$ without exacerbations have an intermediate level of risk associated with ICS withdrawal. The risk of exacerbations after ICS discontinuation is low, but dual bronchodilator therapy should be maintained to make sure that the risk of exacerbations does not increase.

4. Patients with $\mathrm{FEV}_{1}<50 \%$ and exacerbations in the previous year, together with patients with $\mathrm{ACO}$ without exacerbations, may have an increased risk of exacerbations after ICS withdrawal. Discontinuation should be considered only in patients with a significant risk of serious ICS-related adverse effects. In these patients, ICS withdrawal may still be possible provided that dual bronchodilator therapy is maintained, but close follow-up is essential.

An overview of the proposed algorithm is shown in Fig. 2.

\section{Benefits of ICS withdrawal exceed risks}

In patients with $\mathrm{FEV}_{1}>50 \%$ and no exacerbations in the previous year, the benefits of ICS withdrawal exceed the risks and ICS therapy should be discontinued. Evidence supporting ICS withdrawal in these patients is provided by the OPTIMO, [67] INSTEAD, [66] and DACCORD [74] studies, in which patients with mild or moderate COPD had no changes in exacerbations, lung function, or health status following ICS withdrawal.

Studies have also indicated that dual bronchodilator therapy with a LABA/LAMA combination may be used as an alternative to ICS/LABA therapy in patients with moderate-to-severe COPD and a low risk of exacerbations. In this group of patients, LABA/LAMA therapy (indacaterol/glycopyrronium) was associated with improved lung function and lower rates of exacerbation and pneumonia compared with ICS/LABA therapy (fluticasone/salmeterol) in the ILLUMINATE, [48] LANTERN, [49] and CRYSTAL [70] studies. Therefore, patients with an $\mathrm{FEV}_{1}>50 \%$ and no exacerbations in the previous year are candidates for ICS withdrawal, provided that dual bronchodilator therapy is continued [75].

\section{Risks associated with ICS withdrawal exceed benefits}

In patients with $\mathrm{ACO}$ and a history of exacerbations in the previous year, the ICS withdrawal risks are greater than the benefits and ICS should not be discontinued. ACO is recognized as a distinct COPD phenotype, and relevant clinical practice guidelines provide criteria to enable clinicians to identify patients with COPD who 


\begin{tabular}{lccc}
\hline Exacerbation history & \multicolumn{2}{c}{ Patients without ACO } & \multirow{2}{*}{ Patients with ACO } \\
\cline { 2 - 3 } & $\mathrm{FEV}_{1}>50 \%$ & $\mathrm{FEV}_{1}<50 \%$ & \\
\hline No exacerbations in past year & $\mathrm{B}>\mathrm{R}$ & $\mathrm{B}>\mathrm{R}$ & $\mathrm{B}<\mathrm{R}$ \\
Exacerbations ( $\geq 1$ in past year) & $\mathrm{B}>\mathrm{R}$ & $\mathrm{B}=\mathrm{R}$ & $\mathrm{B}<\mathrm{R}$ \\
\hline
\end{tabular}

Fig. 1 Patient categories based on exacerbation history, airflow limitation and the risks of inhaled corticosteroid withdrawal. ACO, asthma-chronic obstructive pulmonary disease overlap; B, benefits of ICS withdrawal; FEV1, forced expiratory volume in $1 \mathrm{~s}$; ICS, inhaled corticosteroid; R, risks associated with ICS withdrawal; dark green = ICS should be discontinued; red = ICS should not be withdrawn; pale green, pale red, or yellow = ICS withdrawal should be carefully evaluated on a case-by-case basis, taking into account the risk of ICS-associated adverse effects

have an asthma component $[8,76]$. The prevalence of ACO among patients with COPD is thought to be up to $20 \%,[20,77-83]$ although prevalence is difficult to stimate as there is no internationally accepted definition of ACO $[84,85]$.

A simplified algorithm for the identification of ACO was proposed following a consensus between the Spanish COPD and asthma guidelines [73]. In this algorithm, the first criterion to be met is a diagnosis of COPD (ie aged $\geq 35$ years, $\geq 10$ pack-year smoker or exsmoker, and post-bronchodilator $\mathrm{FEV}_{1} / \mathrm{FVC}<0.7$ ), after which the diagnostic criteria for asthma are assessed. If the diagnostic criteria for both COPD and asthma are met, a diagnosis of ACO is confirmed; patients who do not meet all of the asthma diagnostic criteria, but have a bronchodilator response of $\geq 400 \mathrm{~mL}$ and $15 \%$ in $\mathrm{FEV}_{1}$ and/or eosinophilia of $\geq 300$ cells $/ \mu \mathrm{L}$ are also classified as having ACO $[73,86]$. Patients with non-completely reversible airflow obstruction but who smoked less than
10 pack-years should be considered and treated like asthmatics.

A post hoc analysis of the WISDOM trial identified a small subgroup of patients with COPD with a significantly increased risk of exacerbations after ICS withdrawal; these patients had a history of frequent exacerbations ( $\geq 2$ per year) and high baseline eosinophil counts $(\geq 300$ or $\geq 400$ cells/ $\mu \mathrm{L}$; defined as ACO according to Spanish guidelines), although a history of frequent exacerbations alone was not predictive of ICS responsiveness in the overall study population [72]. As these patients represented a very small proportion of the total patient population in the WISDOM study, this category is expected to consist of a minority of the patients with COPD.

\section{Intermediate ICS withdrawal risk: benefit ratio}

Patients with $\mathrm{FEV}_{1}>50 \%$ and exacerbations in the previous year and patients with $\mathrm{FEV}_{1}<50 \%$ without exacerbations have an intermediate risk associated with ICS

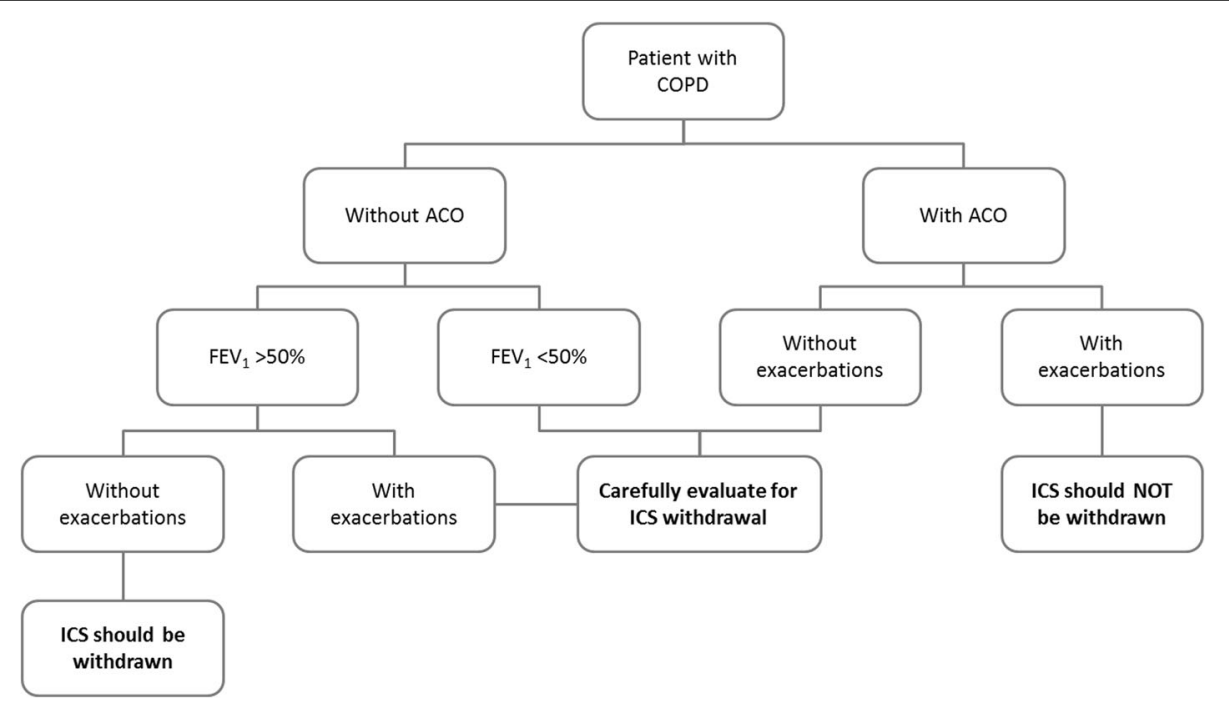

Fig. 2 Proposed algorithm for ICS withdrawal in patients with COPD. ACO, asthma-COPD overlap; COPD, chronic obstructive pulmonary disease; $\mathrm{FEV}_{1}$, forced expiratory volume in $1 \mathrm{~s}$; ICS, inhaled corticosteroid. ACO is diagnosed according to the Spanish consensus as COPD plus asthma diagnosis or COPD and blood eosinophil counts $>300$ cells/ $\mu \mathrm{L}$ and/or a post-bronchodilator response of $>400 \mathrm{~mL}$ and $15 \%$ in $\mathrm{FEV}{ }_{1}$ 
withdrawal. Patients should be individually assessed to determine whether or not ICS therapy should be discontinued, with the risk of ICS-related adverse effects being taken into consideration. This recommendation is supported by evidence from the WISDOM [64] and FLAME [50] studies, in which patients with moderate, severe, or very severe COPD and a history of exacerbations showed no increase in the annual rate of exacerbations after discontinuation of ICS and ongoing dual bronchodilator therapy. In the FLAME study, the rate of pneumonia was lower with LABA/LAMA than ICS/LABA therapy, [50] and a post hoc analysis indicated that the lower rate of exacerbations with LABA/LAMA was independent of blood eosinophil levels [87]. Although the risk of exacerbations may be increased in patients with $\mathrm{FEV}_{1}<50 \%$ and exacerbations in the previous year, as well as patients with ACO without exacerbations, ICS withdrawal needs to be considered in these patients, particularly those with an increased risk of serious ICS-related adverse effects. Following ICS withdrawal, these patients should be maintained on dual bronchodilator therapy and closely followed for exacerbations.

\section{Method of ICS withdrawal}

Based on clinical evidence, ICS therapy may be discontinued abruptly, rather than with gradual dose reduction. In the INSTEAD, [66] FLAME, [50] OPTIMO, [67] CRYSTAL, [70] and DACCORD [74] studies, ICS therapy was withdrawn abruptly with no apparent increase in exacerbations or loss of lung function. WISDOM was the only study in which the ICS dose was decreased in a stepwise fashion [64]. Although ICS withdrawal was associated with a significant decrease in $\mathrm{FEV}_{1}$ in this study, the decline in lung function was only observed after complete ICS discontinuation at 18 weeks and was not progressive $[64,65]$. This suggests that the effect of ICS withdrawal on lung function (if any) only occurs after complete discontinuation, and there is no need to taper the dose in most patients. It should be noted that the LABA used in this study was salmeterol, which has a low intrinsic efficacy and a well-known tolerance in terms of reduction of effect over time [88]. Particular care should be exercised in high-risk patients with frequent exacerbations or poor lung function receiving high doses of ICS, and routine follow-up of patients after ICS withdrawal is recommended.

\section{Conclusions}

Physicians should carefully evaluate patients and provide individualized COPD treatment, especially when considering the initiation of ICS therapy or the safe discontinuation of ICS in patients on long-term therapy. Given the limited efficacy and the potentially serious adverse effects and complications of long-term ICS therapy, the use of
ICS should be limited to the minority of patients with COPD in whom the treatment effects outweigh the risks, and patients for whom safe ICS withdrawal can be achieved should be identified.

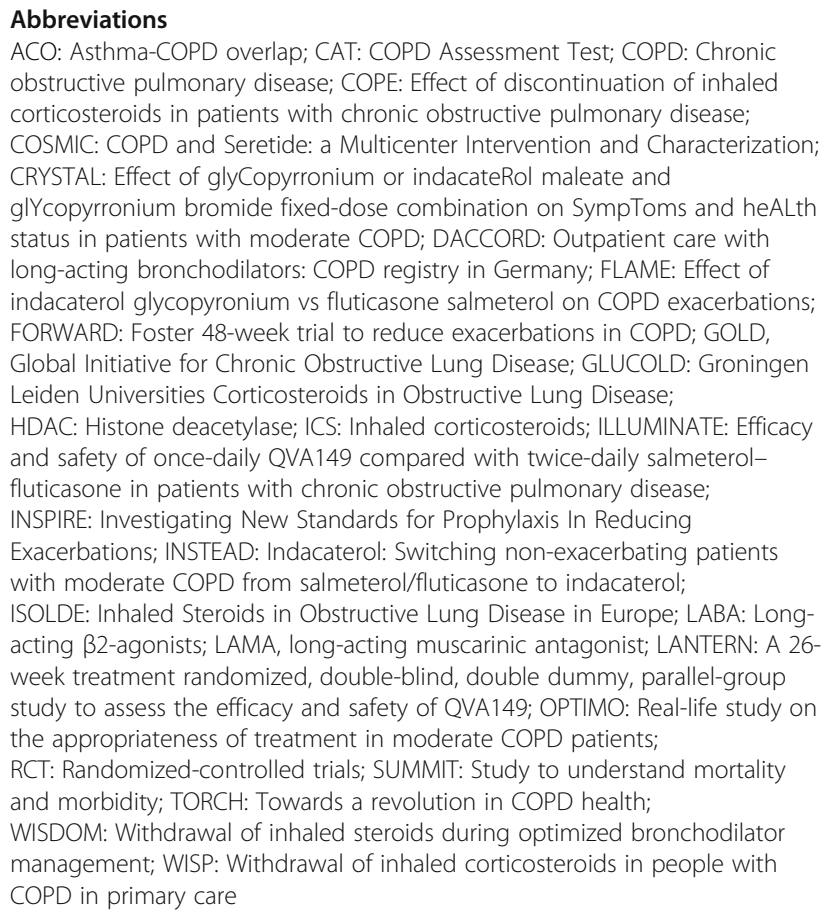

\section{Acknowledgments}

The authors would like to thank Paul Karagounis, who prepared the outline of this manuscript on behalf of Springer Healthcare, and Sarah Greig, PhD, of Springer Healthcare Communications who prepared the first draft of this manuscript. This medical writing assistance was funded by Novartis.

\section{Funding}

This article is a summary of a workshop held in Barcelona, Spain on February 14 2017. The workshop was supported by unrestricted grant from Novartis. The sponsor had no role in the discussion, preparation of manuscript and decision to submit the manuscript for publication.

\section{Availability of data and materials \\ Not applicable}

\section{Authors' contributions}

All authors participated in the round table discussions and drafted, reviewed and approved the final version of the manuscript.

\section{Ethics approval and consent to participate}

Not applicable

\section{Consent for publication}

Not applicable

\section{Competing interests}

MM has received speaker fees from Boehringer Ingelheim, AstraZeneca, Chiesi, GlaxoSmithKline, Menarini, Teva, Grifols, and Novartis, and consulting fees from Boehringer Ingelheim, GlaxoSmithKline, Gebro Pharma, CLS Behring, Cipla, Medilmmune, Mereo Biopharma, Teva, Novartis, and Grifols; BGC has received grants from SEPAR (Sociedad Española de Neumología y Cirugíatorácica), Boehringer Ingelheim, and Menarini, personal fees from AstraZeneca, Rovi, and Esteve, grants and personal fees from Novartis and Chiesi; AA has received grants from SEPAR, Esteve, and NEUMOSUR (Asociación de Neumología y Cirugía Torácica del Sur), and speaker fees 
from Boehringer Ingelheim, AstraZeneca, Chiesi, Gebro Pharma, Grifols, MSD, Mundipharma, Pfizer, and Novartis; MC has received personal fees from Laboratorios Menarini, GSK, and Rovi, and grants from Boehringer Ingelheim; Bernardino Alcázar-Navarrete has received personal fees from GSK, Gebro, and AstraZeneca, grants, personal fees, and non-financial support from Novartis AG and Laboratorios Menarini, and personal fees and non-financial support from Boehringer Ingelheim and Chiesi; CG has received grants from SVN (Sociedad Valenciana de Neumología) and Laboratorios Menarini; grants and speaker fees from Boehringer Ingelheim, Novartis, Rovi, and Teva, speaker fees from AstraZeneca, and grants and consulting fees from Esteve; CE has no conflicts of interest to declare; JAT has received speaker fees from Boehringer Ingelheim, Menarini, Teva, and Novartis, and consulting fees from Boehringer Ingelheim, GlaxoSmithKline, and Esteve; JMRGM has received speaker fees from Boehringer Ingelheim, AstraZeneca, Chiesi, Teva, and Novartis, and consulting fees from Boehringer Ingelheim and Teva; JAQJ has received speaker fees from Esteve, Teva, Gebro, and Grifols, and consulting fees from Boehringer Ingelheim and Teva; and Adolfo Baloira has received speaker fees from Boehringer Ingelheim, AstraZeneca, Chiesi, GlaxoSmithKline, Esteve, Ferrer, Menarini, Teva, Grifols, and Novartis, and consulting fees from Boehringer Ingelheim, GlaxoSmithKline, Esteve, Teva, Novartis, and Grifols.

\section{Publisher's Note}

Springer Nature remains neutral with regard to jurisdictional claims in published maps and institutional affiliations.

\section{Author details}

${ }^{1}$ Pneumology Department, Hospital Universitari Vall d'Hebron, P. Vall d'Hebron 119-129, 08035 Barcelona, Spain. ${ }^{2}$ CIBER de Enfermedades Respiratorias (CIBERES), Barcelona, Spain. ${ }^{3}$ Department of Respiratory Medicine, Hospital Universitario Son Espases-IdISBa, Palma de Mallorca, Spain. ${ }^{4}$ Pneumology, Allergy and Thoracic Surgery Department, Hospital Universitario Puerta del Mar, Cádiz, Spain. ${ }^{5}$ Medicine Department, University of Cádiz, Cádiz, Spain. ${ }^{6}$ Pulmonary Department, Instituto de Investigación Sanitaria del Hospital Clínico San Carlos (IdISSC), Hospital Clínico San Carlos, Madrid, Spain. ${ }^{7}$ Departamento de Medicina, Facultad de Medicina, Universidad Complutense de Madrid, Madrid, Spain. ${ }^{8}$ Respiratory Department, AIG de Medicina, Hospital de Alta Resolución de Loja, Agencia Sanitaria Hospital de Poniente, Loja, Granada, Spain. ${ }^{9}$ Department of Respiratory Medicine, Hospital Clínico Universitario and Instituto de Investigación Sanitaria (INCLIVA) Valencia, Valencia, Spain. ${ }^{10}$ Pneumology Department of Hospital Galdakao-Usansolo, Biscay, Spain. ${ }^{11}$ Red de Investigación en Servicios Sanitarios y Enfermedades Crónicas (REDISSEC), Bilbao, Spain. ${ }^{12}$ Health Center Menasalbas, Autonomic Health Service, Toledo, Spain. ${ }^{13}$ Pneumology Department, Hospital Universitary "Príncipe de Asturias", Alcalá de Henares, Madrid, Spain. ${ }^{14}$ Centro de Salud Lucena I, Lucena, Córdoba, Spain. ${ }^{15}$ Servicio de Neumología, Complejo Hospitalario Universitario de Pontevedra, Pontevedra, Spain.

Received: 23 October 2017 Accepted: 15 November 2017 Published online: 28 November 2017

\section{References}

1. Lozano R, Naghavi M, Foreman K, et al. Global and regional mortality from 235 causes of death for 20 age groups in 1990 and 2010: a systematic analysis for the global burden of disease study 2010. Lancet. 2012;380:2095-128.

2. Vogelmeier CF, Criner GJ, Martinez FJ, et al. Global strategy for the diagnosis, management, and prevention of chronic obstructive lung disease 2017 report: GOLD executive summary. Arch Bronconeumol. 2017;53:128-49.

3. Miravitlles $M$, Vogelmeier $C$, Roche $N$, et al. A review of national guidelines for management of COPD in Europe. Eur Respir J. 2016;47:625-37.

4. Nannini $L J$, Lasserson TJ, Poole P. Combined corticosteroid and long-acting beta2-agonist in one inhaler versus long-acting beta2-agonists for chronic obstructive pulmonary disease. Cochrane Database Syst Rev. 2012: CD006829.

5. Nannini $L$, Poole P, Milan SJ et al. Combined corticosteroid and long-acting beta $_{2}$-agonist in one inhaler versus inhaled corticosteroids alone for chronic obstructive pulmonary disease. Cochrane Database Syst Rev. 2013: CD006826.
6. D'Urzo A, Donohue JF, Kardos P, et al. A re-evaluation of the role of inhaled corticosteroids in the management of patients with chronic obstructive pulmonary disease. Expert Opin Pharmacother. 2015;16:1845-60.

7. Barrecheguren M, Monteagudo M, Ferrer J, et al. Treatment patterns in COPD patients newly diagnosed in primary care. A population-based study. Respir Med. 2016;111:47-53.

8. Miravitlles M, Soler-Cataluna JJ, Calle M, et al. Spanish guidelines for management of chronic obstructive pulmonary disease (GesEPOC) 2017. Pharmacological treatment of stable phase. Arch Bronconeumol. 2017;53:324-35.

9. Crim C, Dransfield MT, Bourbeau J, et al. Pneumonia risk with inhaled fluticasone furoate and vilanterol compared with vilanterol alone in patients with COPD. Ann Am Thorac Soc. 2015;12:27-34

10. Nieto A, Mazon A, Pamies R, et al. Adverse effects of inhaled corticosteroids in funded and nonfunded studies. Arch Intern Med. 2007;167:2047-53.

11. Agusti A, Hurd S, Jones P, et al. FAQs about the GOLD 2011 assessment proposal of COPD: a comparative analysis of four different cohorts. Eur Respir J. 2013;42:1391-401.

12. Vestbo J, Vogelmeier C, Small M, et al. Understanding the GOLD 2011 strategy as applied to a real-world COPD population. Respir Med. 2014; 108:729-36.

13. Reddel HK, Valenti $L$, Easton $K L$, et al. Assessment and management of asthma and chronic obstructive pulmonary disease in Australian general practice. Aust Fam Physician. 2017;46:413-9.

14. Price D, West D, Brusselle $G$, et al. Management of COPD in the UK primarycare setting: an analysis of real-life prescribing patterns. Int J Chron Obstruct Pulmon Dis. 2014;9:889-904.

15. Izquierdo $J$, Martin A, de Lucas $P$, et al. Misdiagnosis of patients receiving inhaled therapies in primary care. Int J Chron Obstruct Pulmon Dis. 2010;5:241-9.

16. Burgel PR, Deslee G, Jebrak G, et al. Real-life use of inhaled corticosteroids in COPD patients versus the GOLD proposals: a paradigm shift in GOLD 2011? Eur Respir J. 2014;43:1201-3.

17. Roche N, Pribil C, Van Ganse E, et al. Real-life use of fluticasone propionate/ salmeterol in patients with chronic obstructive pulmonary disease: a French observational study. BMC Pulm Med. 2014;14:56

18. Calle Rubio M, Alcazar Navarrete B, Soriano JB, et al. Clinical audit of COPD in outpatient respiratory clinics in Spain: the EPOCONSUL study. Int J Chron Obstruct Pulmon Dis. 2017;12:417-26.

19. Ernst P, Saad N, Suissa S. Inhaled corticosteroids in COPD: the clinical evidence. Eur Respir J. 2015;45:525-37.

20. Price D, Yawn B, Brusselle $G$, et al. Risk-to-benefit ratio of inhaled corticosteroids in patients with COPD. Prim Care Respir J. 2013;22:92-100.

21. Alcázar-Navarrete B, Casanova C, Miravitlles M, et al. Correct use of inhaled corticosteroids in chronic obstructive pulmonary disease: a consensus document. Arch Bronconeumol. 2015;51:193-8.

22. Harlander M, Barrecheguren M, Turel M, et al. Should patients switched from D to B in the GOLD 2017 classification be discontinued from inhaled corticosteroids? COPD. 2017;14:465-8.

23. Kaplan AG. Applying the wisdom of stepping down inhaled corticosteroids in patients with COPD: a proposed algorithm for clinical practice. Int $J$ Chron Obstruct Pulmon Dis. 2015;10:2535-48.

24. Tariq SM, Thomas EC. Maintenance therapy in COPD: time to phase out ICS and switch to the new LAMA/LABA inhalers? Int J Chron Obstruct Pulmon Dis. 2017;12:1877-82.

25. Cabrera C, Casanova C, Martin Y, et al. Agreement between a simple dyspnea-guided treatment algorithm for stable COPD and the GOLD guidelines: a pilot study. Int J Chron Obstruct Pulmon Dis. 2016;11:1217-22.

26. Miravitlles M, Anzueto A. A new two-step algorithm for the treatment of COPD. Eur Respir J. 2017;49:1602200.

27. Ito K, Barnes PJ, Adcock IM. Glucocorticoid receptor recruitment of histone deacetylase 2 inhibits interleukin-1ß-induced histone $\mathrm{H} 4$ acetylation on lysines 8 and 12. Mol Cell Biol. 2000;20:6891-903.

28. Barnes PJ, Ito K, Adcock IM. Corticosteroid resistance in chronic obstructive pulmonary disease: inactivation of histone deacetylase. Lancet. 2004:363:731-3.

29. Ito K, Ito M, Elliott WM, et al. Decreased histone deacetylase activity in chronic obstructive pulmonary disease. N Engl J Med. 2005;352:1967-76.

30. Barnes NC, Qiu YS, Pavord ID, et al. Antiinflammatory effects of salmeterol/ fluticasone propionate in chronic obstructive lung disease. Am J Respir Crit Care Med. 2006;173:736-43. 
31. Lapperre TS, Snoeck-Stroband JB, Gosman MM, et al. Effect of fluticasone with and without salmeterol on pulmonary outcomes in chronic obstructive pulmonary disease: a randomized trial. Ann Intern Med. 2009;151:517-27.

32. Kunz LIZ, Ten Hacken NH, Lapperre TS, et al. Airway inflammation in COPD after long-term withdrawal of inhaled corticosteroids. Eur Respir J. 2017:49:1700848.

33. Asai K, Kobayashi A, Makihara Y, et al. Anti-inflammatory effects of salmeterol/fluticasone propionate $50 / 250 \mathrm{mcg}$ combination therapy in Japanese patients with chronic obstructive pulmonary disease. Int J Chron Obstruct Pulmon Dis. 2015:10:803-11.

34. Saha S, Brightling CE. Eosinophilic airway inflammation in COPD. Int J Chron Obstruct Pulmon Dis. 2006;1:39-47.

35. Bafadhel M, McKenna S, Terry S, et al. Acute exacerbations of chronic obstructive pulmonary disease: identification of biologic clusters and their biomarkers. Am J Respir Crit Care Med. 2011;184:662-71.

36. Vedel-Krogh S, Nielsen SF, Lange P, et al. Blood eosinophils and exacerbations in chronic obstructive pulmonary disease. The Copenhagen general population study. Am J Respir Crit Care Med. 2016;193:965-74.

37. Barnes NC, Sharma R, Lettis $S$, et al. Blood eosinophils as a marker of response to inhaled corticosteroids in COPD. Eur Respir J. 2016;47:1374-82.

38. Hinds DR, DiSantostefano RL, Le HV, et al. Identification of responders to inhaled corticosteroids in a chronic obstructive pulmonary disease population using cluster analysis. BMJ Open. 2016;6:e010099.

39. Siddiqui SH, Guasconi A, Vestbo J, et al. Blood eosinophils: a biomarker of response to extrafine beclomethasone/formoterol in chronic obstructive pulmonary disease. Am J Respir Crit Care Med. 2015;192:523-5.

40. Burge PS, Calverley PM, Jones PW, et al. Randomised, double blind, placebo controlled study of fluticasone propionate in patients with moderate to severe chronic obstructive pulmonary disease: the ISOLDE trial. BMJ. 2000; 320:1297-303

41. Paggiaro PL, Dahle R, Bakran I, et al. Multicentre randomised placebocontrolled trial of inhaled fluticasone propionate in patients with chronic obstructive pulmonary disease. International COPD Study Group. Lancet. 1998:351:773-80.

42. Calverley PM, Anderson JA, Celli B, et al. Salmeterol and fluticasone propionate and survival in chronic obstructive pulmonary disease. N Engl Med. 2007;356:775-89.

43. Suissa S, Ernst P. Mega trials in COPD-clinical data analysis and design issues. Pneumonol Alergol Pol. 2011;79:227-31.

44. Vestbo J, Anderson JA, Brook RD, et al. Fluticasone furoate and vilanterol and survival in chronic obstructive pulmonary disease with heightened cardiovascular risk (SUMMIT): a double-blind randomised controlled trial. Lancet. 2016;387:1817-26.

45. Siva $R$, Green $R H$, Brightling $C E$, et al. Eosinophilic airway inflammation and exacerbations of COPD: a randomised controlled trial. Eur Respir J. 2007;29:906-13.

46. Pascoe S, Locantore N, Dransfield MT, et al. Blood eosinophil counts, exacerbations, and response to the addition of inhaled fluticasone furoate to vilanterol in patients with chronic obstructive pulmonary disease: a secondary analysis of data from two parallel randomised controlled trials. Lancet Respir Med. 2015;3:435-42.

47. Wedzicha JA, Calverley PM, Seemungal TA, et al. The prevention of chronic obstructive pulmonary disease exacerbations by salmeterol/fluticasone propionate or tiotropium bromide. Am J Respir Crit Care Med. 2008;177:19-26.

48. Vogelmeier CF, Bateman ED, Pallante J, et al. Efficacy and safety of once-daily QVA149 compared with twice-daily salmeterol-fluticasone in patients with chronic obstructive pulmonary disease (ILLUMINATE): a randomised, double-blind, parallel group study. Lancet Respir Med. 2013:1:51-60.

49. Zhong N, Wang C, Zhou X, et al. LANTERN: a randomized study of QVA149 versus salmeterol/fluticasone combination in patients with COPD. Int $J$ Chron Obstruct Pulmon Dis. 2015;10:1015-26.

50. Wedzicha JA, Banerji D, Chapman KR, et al. Indacaterol-glycopyrronium versus salmeterol-fluticasone for COPD. N Engl J Med. 2016;374:2222-34.

51. Singh S, Loke YK. Risk of pneumonia associated with long-term use of inhaled corticosteroids in chronic obstructive pulmonary disease: a critical review and update. Curr Opin Pulm Med. 2010;16:118-22.

52. Janson C, Larsson $\mathrm{K}$, Lisspers $\mathrm{KH}$, et al. Pneumonia and pneumonia related mortality in patients with COPD treated with fixed combinations of inhaled corticosteroid and long acting beta2 agonist: observational matched cohort study (PATHOS). BMJ. 2013;346:13306.
53. Loke YK, Cavallazzi R, Singh S. Risk of fractures with inhaled corticosteroids in COPD: systematic review and meta-analysis of randomised controlled trials and observational studies. Thorax. 2011;66:699-708.

54. Lehouck A, Boonen S, Decramer M, et al. COPD, bone metabolism, and osteoporosis. Chest. 2011;139:648-57.

55. Suissa S, Kezouh A, Ernst P. Inhaled corticosteroids and the risks of diabetes onset and progression. Am J Med. 2010;123:1001-6.

56. Wang JJ, Rochtchina E, Tan AG, et al. Use of inhaled and oral corticosteroids and the long-term risk of cataract. Ophthalmology. 2009;116:652-7.

57. Dong $\mathrm{YH}$, Chang $\mathrm{CH}, \mathrm{Wu} \mathrm{FL}$, et al. Use of inhaled corticosteroids in patients with COPD and the risk of TB and influenza: a systematic review and metaanalysis of randomized controlled trials. A systematic review and metaanalysis of randomized controlled trials. Chest. 2014;145:1286-97.

58. Jarad NA, Wedzicha JA, Burge PS, et al. An observational study of inhaled corticosteroid withdrawal in stable chronic obstructive pulmonary disease. ISOLDE Study Group. Respir Med. 1999;93:161-6.

59. van der Valk P, Monninkhof E, van der Palen J, et al. Effect of discontinuation of inhaled corticosteroids in patients with chronic obstructive pulmonary disease: the COPE study. Am J Respir Crit Care Med. 2002;166:1358-63.

60. Wouters EF, Postma DS, Fokkens B, et al. Withdrawal of fluticasone propionate from combined salmeterol/fluticasone treatment in patients with COPD causes immediate and sustained disease deterioration: a randomised controlled trial. Thorax. 2005;60:480-7.

61. Choudhury AB, Dawson CM, Kilvington HE, et al. Withdrawal of inhaled corticosteroids in people with COPD in primary care: a randomised controlled trial. Respir Res. 2007;8:93.

62. Nadeem NJ, Taylor SJ, Eldridge SM. Withdrawal of inhaled corticosteroids in individuals with COPD - a systematic review and comment on trial methodology. Respir Res. 2011;12:107.

63. Calzetta L, Matera MG, Braido F, et al. Withdrawal of inhaled corticosteroids in COPD: a meta-analysis. Pulm Pharmacol Ther. 2017;45:148-58.

64. Magnussen $H$, Disse $B$, Rodriguez-Roisin $R$, et al. Withdrawal of inhaled glucocorticoids and exacerbations of COPD. N Engl J Med. 2014;371:1285-94.

65. Magnussen $\mathrm{H}$, Tetzlaff $\mathrm{K}$, Bateman ED, et al. Lung function changes over time following withdrawal of inhaled corticosteroids in patients with severe COPD. Eur Respir J. 2016;47:651-4.

66. Rossi A, van der Molen T, del Olmo R, et al. INSTEAD: a randomised switch trial of indacaterol versus salmeterol/fluticasone in moderate COPD. Eur Respir J. 2014;44:1548-56.

67. Rossi A, Guerriero M, Corrado A. Withdrawal of inhaled corticosteroids can be safe in COPD patients at low risk of exacerbation: a real-life study on the appropriateness of treatment in moderate COPD patients (OPTIMO). Respir Res. 2014;15:77

68. Vogelmeier C, Worth $\mathrm{H}$, Buhl R, et al. "real-life" inhaled corticosteroid withdrawal in COPD: a subgroup analysis of DACCORD. Int J Chron Obstruct Pulmon Dis. 2017;12:487-94.

69. Suissa S, Coulombe J, Ernst P. Discontinuation of inhaled corticosteroids in COPD and the risk reduction of pneumonia. Chest. 2015;148:1177-83.

70. Vogelmeier CF, Gaga M, Aalamian-Mattheis M, et al. Efficacy and safety of direct switch to indacaterol/glycopyrronium in patients with moderate COPD: the CRYSTAL open-label randomised trial. Respir Res. 2017;18:140.

71. Watz H, Tetzlaff K, Wouters EF, et al. Blood eosinophil count and exacerbations in severe chronic obstructive pulmonary disease after withdrawal of inhaled corticosteroids: a post-hoc analysis of the WISDOM trial. Lancet Respir Med. 2016;4:390-8.

72. Calverley PMA, Tetzlaff K, Vogelmeier C, et al. Eosinophilia, frequent exacerbations, and steroid response in chronic obstructive pulmonary disease. Am J Respir Crit Care Med. 2017;196:1219-21.

73. Miravitlles M, Alvarez-Gutierrez FJ, Calle M, et al. Algorithm for identification of asthma-COPD overlap: consensus between the Spanish COPD and asthma guidelines. Eur Respir J. 2017;49:1700068.

74. Kardos $\mathrm{P}$, Vogelmeier $\mathrm{C}$, Worth $\mathrm{H}$, et al. A two-year evaluation of the 'real life' impact of COPD on patients in Germany: the DACCORD observational study. Respir Med. 2017;124:57-64.

75. Miravitlles M, Anzueto A, Jardim JR. Optimizing bronchodilation in the prevention of COPD exacerbations. Respir Res. 2017;18:125.

76. Soler-Cataluña JJ, Cosío B, Izquierdo JL, et al. Consensus document on the overlap phenotype COPD-asthma in COPD. Arch Bronconeumol. 2012:48:331-7. 
77. Barrecheguren M, Esquinas C, Miravitlles M. The asthma-chronic obstructive pulmonary disease overlap syndrome (ACOS): opportunities and challenges. Curr Opin Pulm Med. 2015;21:74-9.

78. Cosio BG, Soriano JB, López-Campos JL, et al. Defining the asthma-COPD overlap syndrome in a COPD cohort. Chest. 2016;149:45-52.

79. Izquierdo-Alonso JL, Rodriguez-Gonzalezmoro JM, de Lucas-Ramos P, et al. Prevalence and characteristics of three clinical phenotypes of chronic obstructive pulmonary disease (COPD). Respir Med. 2013;107:724-31.

80. Miravitlles M, Barrecheguren M, Roman-Rodriguez M. Frequency and characteristics of different clinical phenotypes of chronic obstructive pulmonary disease. Int J Tuberc Lung Dis. 2015;19:992-8.

81. Barrecheguren M, Roman-Rodriguez M, Miravitlles M. Is a previous diagnosis of asthma a reliable criterion for asthma-COPD overlap syndrome in a patient with COPD? Int J Chron Obstruct Pulmon Dis. 2015;10:1745-52.

82. Alcázar-Navarrete B, Romero-Palacios PJ, Ruiz-Sancho A, et al. Diagnostic performance of the measurement of nitric oxide in exhaled air in the diagnosis of COPD phenotypes. Nitric Oxide. 2016:54:67-72.

83. Calle Rubio M, Casamor R, Miravitlles M. Identification and distribution of COPD phenotypes in clinical practice according to Spanish COPD guidelines: the FENEPOC study. Int J Chron Obstruct Pulmon Dis 2017;12: 2373-2383.

84. Bujarski S, Parulekar AD, Sharafkhaneh A, et al. The asthma COPD overlap syndrome (ACOS). Curr Allergy Asthma Rep. 2015;15:509.

85. Sin DD, Miravitlles M, Mannino DM, et al. What is asthma-COPD overlap syndrome? Towards a consensus definition from a round table discussion. Eur Respir J. 2016:48:664-73.

86. Plaza V, Alvarez F, Calle M, et al. Consensus on the asthma-COPD overlap syndrome (ACOS) between the Spanish COPD guidelines (GesEPOC) and the Spanish guidelines on the Management of Asthma (GEMA). Arch Bronconeumol. 2017:53:443-9.

87. Roche N, Chapman KR, Vogelmeier CF, et al. Blood eosinophils and response to maintenance chronic obstructive pulmonary disease treatment. Data from the FLAME trial. Am J Respir Crit Care Med. 2017:195:1189-97.

88. Donohue JF, Menjoge S, Kesten S. Tolerance to bronchodilating effects of salmeterol in COPD. Respir Med. 2003:97:1014-20.

\section{Submit your next manuscript to BioMed Central and we will help you at every step:}

- We accept pre-submission inquiries

- Our selector tool helps you to find the most relevant journal

- We provide round the clock customer support

- Convenient online submission

- Thorough peer review

- Inclusion in PubMed and all major indexing services

- Maximum visibility for your research

Submit your manuscript at www.biomedcentral.com/submit 